\title{
Management Competency Model: Predictive Neural Network Approach for Empirical Components of Construction Project Proficiency
}

\author{
Dante L. SILVA ${ }^{\mathrm{a}}{ }^{1}$, Kevin Lawrence M. De JESUS ${ }^{\mathrm{b}}$, Bernard S. VILLAVERDE ${ }^{\mathrm{a}}$, \\ Edgar M. ADINA ${ }^{\mathrm{a}}$ \\ ${ }^{a}$ School of Civil, Environmental and Geological Engineering, Mapua University, 658 \\ Muralla St., Intramuros, Manila 1002, Philippines \\ ${ }^{b}$ School of Graduate Studies, Mapua University, 658 Muralla St., Intramuros, Manila \\ 1002, Philippines
}

\begin{abstract}
Management competencies are skills that incorporate the understanding, proficiencies and qualities essential for successful performance. Individuals in the top of the organizational hierarchy presents himself being an effective leader by immersing to a readily difficult activity in the project. Molding the important management competencies was found to be hard since the efficacy of a competent construction manager is dependent on countless administrative aspects. The current study intended to offer a construction management competency for human resource development in construction companies. Utilizing this competency model, the company could increase its performance capacity and productivity. This study developed a competency theory and a hybrid predictive model with specific foci on construction managers. The Management Competency Framework Assessment Instrument was developed, following an approach through factor-item analytic mode. Furthermore, this research constructs a predictive performance model using Artificial Neural Network through the factors associated to successful management performance. A sensitivity analysis was also implemented to assess the relative importance of individual factors to the effective construction performance.
\end{abstract}

Keywords: Management competency model, artificial neural network, construction project proficiency, sensitivity analysis

\section{Introduction}

One of the most difficult undertakings in a construction project is the selection of the most suitable individual for the job. Currently, project managers in the construction industry requires versatility and adaptability to multiple functions and roles wherein a key element is their knowledge and skills gained from years of experience and training $[1,2]$. The management competency is classified into four areas: self - awareness,

${ }^{1}$ Corresponding author: Dante L. Silva, School of Civil, Environmental and Geological Engineering, Mapua University, 658 Muralla St., Intramuros, Manila 1002, Philippines; E-mail: dantesilva2000@yahoo.com. 
systems thinking, action management and solution focus as shown in Figure 1. Self awareness is a management competency which refers to how a person analyzes situations carefully and makes rational judgments and logical decisions. Personal values and self - image (A1) and ability, knowledge and expertise (A2) were the subsets under this management competency area. Systems thinking is a driver of how thinking about problems and strategies should be approached within the organization. Under this management competency area, it includes people management and authentic leadership (B3) and interpersonal and entrepreneurial skills (B4). Action Management refers to the act, manner or practice of managing changes and innovations and handling differences. It includes managing change and differences (C5) as well as innovation management (C6). The last area of professional management competency is the solution focus which is the knowing the important results and focusing resources to achieve clear outputs. It involves sustainable management (D7) and achievement and results orientation (D8) [3].

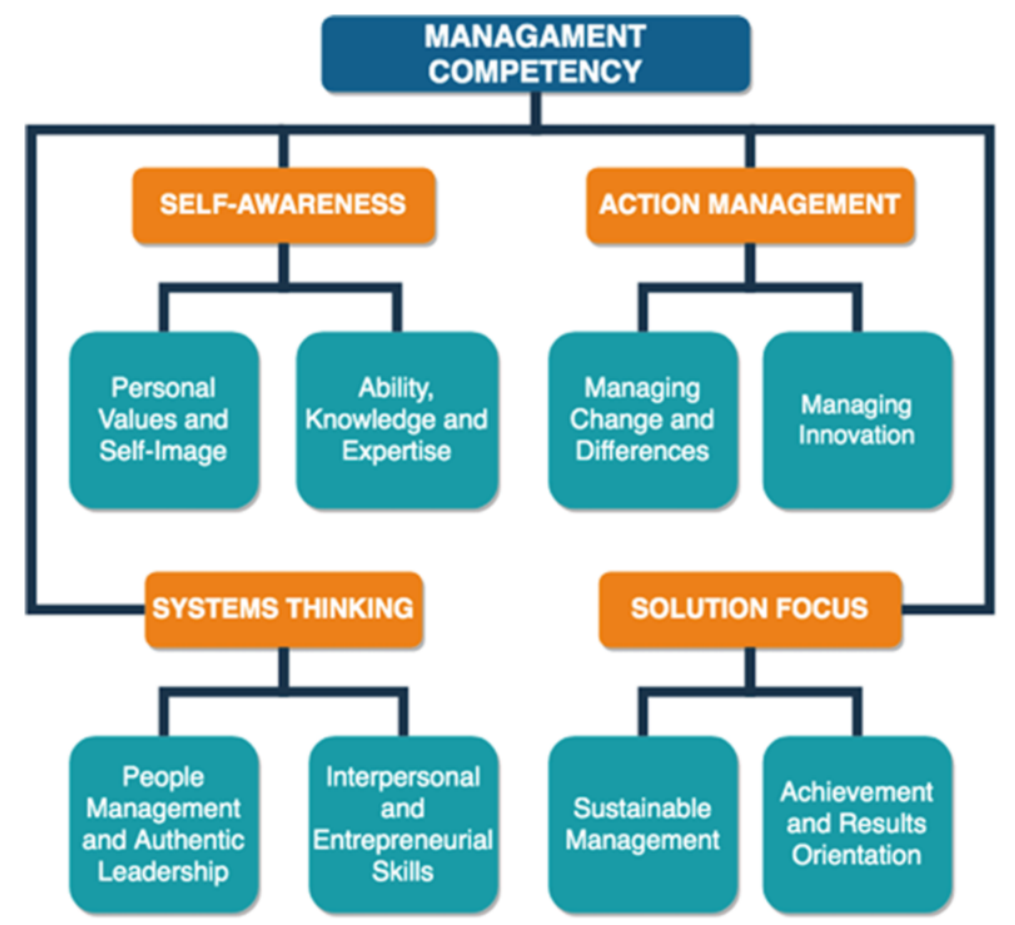

Figure 1. Management competency areas.

Assessment of the competency for successful project management performance is a major challenge in the construction industry. Lack of project management competency may result to issues and problems in the costs, delays, labor productivity and safety in the construction site. The use of machine learning techniques such as Artificial Neural Network (ANN) may assist in addressing the issue of competency assessment [4].

The use of the machine learning techniques was steadily increasing over the years. In the construction management, the use of machine learning techniques such as neural network was implemented in prediction of safe work behavior [5], construction labor 
productivity [6], construction project manager's motivators and human values [7] and change orders [8]. The use of neural network as prediction is due to its ability to model complex and non-linear functions and minimum statistical requirements.

This study established a neural network model for predicting construction project competency using different management competency subsets. Moreover, the relative importance of these subsets to the construction project management competency rating was calculated.

\section{Methodology}

\subsection{Research Framework}

The flow of the implementation of the study for the prediction of the management competency rating as well as calculation of the most influencing factors were displayed in Figure 2.

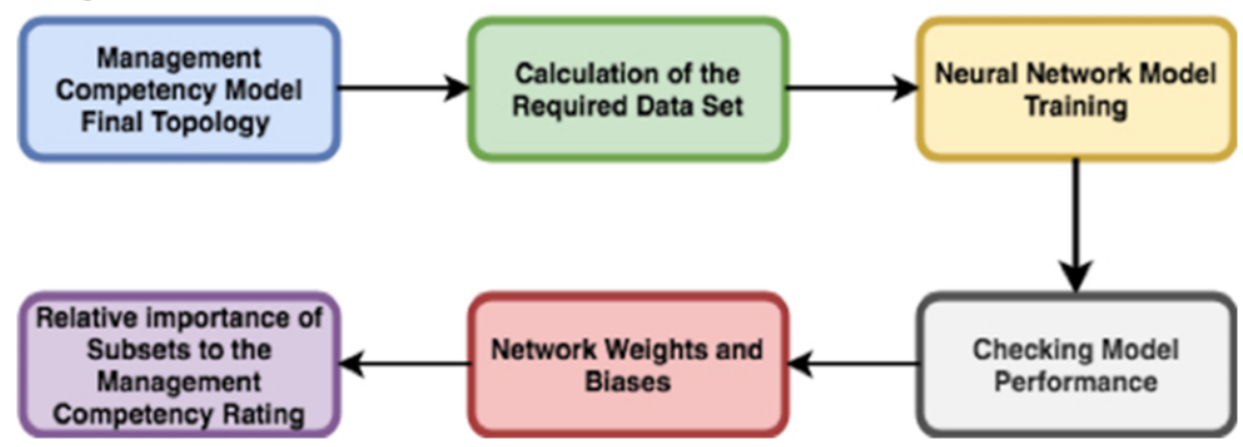

Figure 2. Framework of the study.

\subsection{Data Collection}

The number of respondents used in this study is established on the suggested topology of the ANN model wherein the quantity of hidden neurons is signified by " $m$ " quantity of input parameters [9]. These suggested quantity of hidden neurons for an ANN model was used to calculate the range of the required number of data sets [10] as shown in equation (1) and (2).

$$
\begin{aligned}
& M I N=H I+O H \\
& M A X=H(I+1)+O(H+1)
\end{aligned}
$$

where "I" is the quantity of input parameters, " $\mathrm{H}$ " is the quantity of hidden neurons and "O" is the quantity of output parameters. Using this equation, this study arrived with the 81 respondents required for the training of the network. 


\subsection{Neural Network Modelling}

The management competency rating model was created using the MATLAB R2019a Neural Network Toolbox ${ }^{\mathrm{TM}}$. The data gathered from the respondents were partitioned into three groups: $70 \%$ were used for training, $15 \%$ for validation and $15 \%$ for testing [11]. Using the governing design of the model which is 8-8-1 (input neurons-hidden neurons-output neuron).

The datasets were trained and the developed management competency rating model was determined. The governing characteristics of the model is shown in Table 1.

Table 1. Governing characteristics of the management competency model.

\begin{tabular}{ll}
\hline Internal Characteristics & Value \\
\hline Training Algorithm & Levenberg - Marquardt [12] \\
Transfer Function & Hyperbolic Tangent Sigmoid [12] \\
Number of Hidden Neurons & 8 \\
Number of Hidden Layers & 2 (1 Hidden Layer and 1 Output Layer) \\
Performance Indicators & R, MSE and MAPE [13] \\
\hline
\end{tabular}

The developed model was obtained using different performance indicators as shown in equation (3) - Pearson's Correlation Coefficient, equation (4) - Mean Squared Error (MSE) and equation (5) - Mean Absolute Percentage Error (MAPE).

$$
\begin{gathered}
R=\frac{\sum_{j=1}^{n}\left(x_{j}-\overline{x_{j}}\right)\left(z_{j}-\overline{z_{j}}\right)}{\sqrt{\sum_{j=1}^{n}\left(x_{j}-\overline{x_{j}}\right) \sum_{j=1}^{n}\left(z_{j}-\overline{z_{j}}\right)^{2}}} \\
M S E=\frac{1}{n} \sum_{j=1}^{n}\left(x_{j}-z_{j}\right)^{2} \\
M A P E=\frac{1}{n} \sum_{j=1}^{n} \frac{\left|\overline{y_{j}}-y_{j}\right|}{y_{j}} \times 100
\end{gathered}
$$

where the $x_{j}, y_{j}$ and $z_{j}$ represents the actual value, determined value for " $\mathrm{j}$ " variable and predicted value, respectively while $\bar{x}_{J}, \bar{y}_{J}$ and $\bar{z}_{J}$ indicates the average of the targeted real value, predicted output and predicted value by the ANN for parameter " $\mathrm{j}$ ", respectively [14].

\subsection{Sensitivity Analysis}

A sensitivity analysis was implemented to determine the influence of individual input parameter to the management competency rating and its variability. Since this study includes multiple input parameters, the sensitivity analysis is the principal tool for evaluation of the variation of the output and provided an explanatory analysis on the input parameter influence to the model output [15]. 
The Garson's Algorithm was utilized to assess the impact of input parameters individually to the management competency rating. The relative importance of input variables to the target variable is established on the weights of the connections which is given by Equation (6).

$$
R I=\frac{\sum_{b=1}^{n}\left[\frac{\left|w_{a b}\right|}{\sum_{i=1}^{m}\left|w_{i b}\right|}\left|w_{b c}\right|\right]}{\sum_{a=1}^{m}\left\{\sum_{b=1}^{n}\left[\frac{\left.\left.w_{a b}\left|w_{b c}\right|\right]\right\}}{\sum_{i=1}^{m} w_{i b}}\right]\right\}}
$$

where RI is the relative importance of the input parameters to the management competency rating, "a" is the quantity of input variables, "b" is the quantity of hidden neurons and "c" is the quantity of output variables [16].

\section{Results and discussion}

\subsection{Neural Network Modelling}

Neural network model development which is best suitable to for this study, is mainly relying on the architecture of the network. Using the related literature for neural network model development, the final topology and architecture of the model was identified and determined to be 8-8-1 (input-hidden-output) and shown in Figure 3.

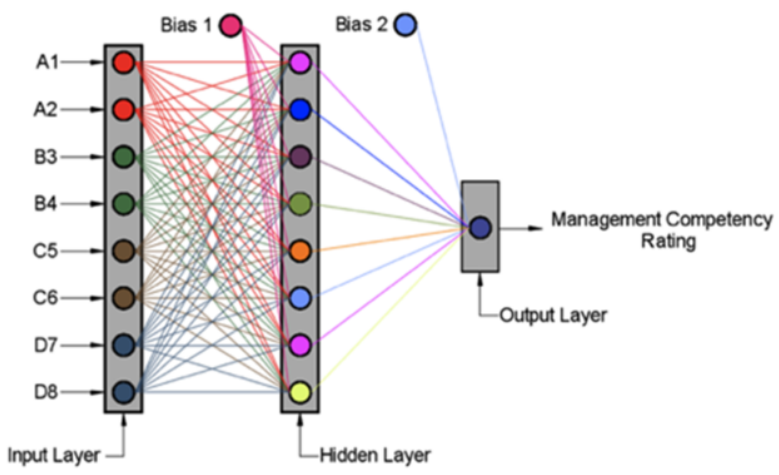

Figure 3. Architecture of the management competency rating model.

The performance of the developed management competency model has an extremely high $R_{\text {all }}$ value and very low MSE and MAPE. The performance and 
correlation plots of the developed management competency model were shown in Figure $4 a$ and $4 b$.

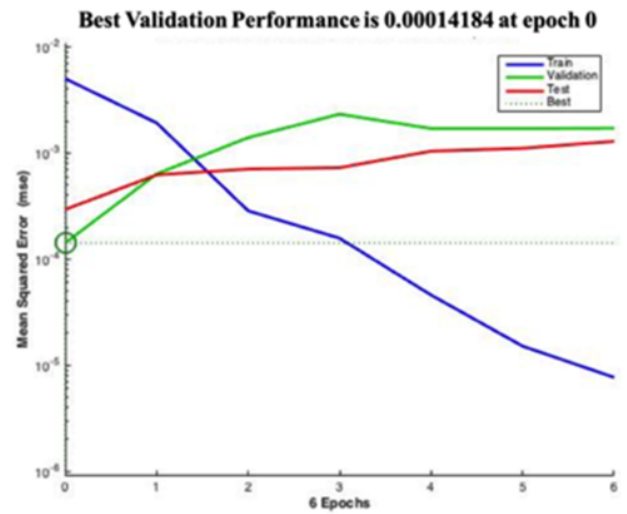

(a)
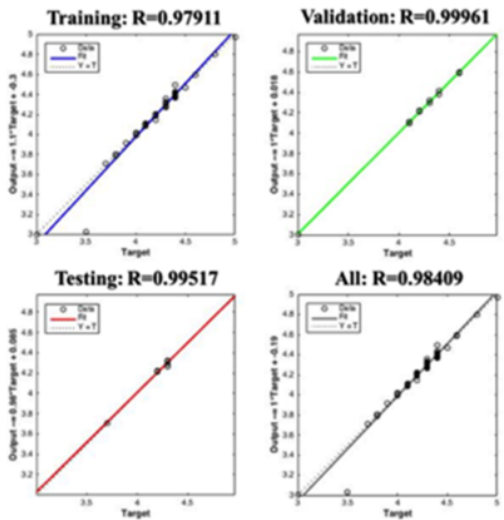

(b)

Figure 4. (a) Performance plot and (b) Correlation plots of the developed management competency model.

The performance of the developed management competency model comprises of plots from three distinctive phases of the model development - training, validation and testing phases which was pre-assigned in the Neural Network Toolbox as $70 \%, 15 \%$ and $15 \%$, respectively, from the entire dataset. The regression values for the developed management competency model were $0.97911,0.99961,0.99517$ and 0.98409 , for training, validation and testing, respectively. The performance of the model was MSE equal to 0.00014184 , MAPE of $0.66393559 \%$ and $\mathrm{R}=0.98415$ between actual and predicted management competency rating as shown in Figure 5.

\subsection{Sensitivity Analysis}

In determining the influence of individual input variable to the management competency rating, sensitivity analysis using Garson's Algorithm was executed. Table 2 presents the product weights of the management competency rating model and the impact of the individual input variable to the management competency rating model.

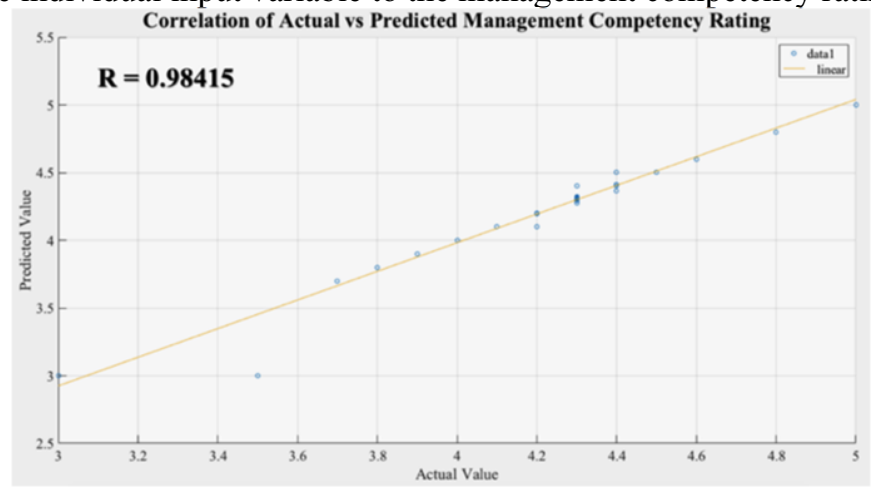

Figure 5. Correlation of actual vs. Predicted management competency rating. 
Table 2. Product weights of the management competency rating model.

\begin{tabular}{lllllllll}
\hline & A1 & A2 & B3 & B4 & C5 & C6 & D7 & D8 \\
\hline Hidden 1 & 0.1807 & 0.1852 & 0.0707 & 0.0638 & 0.0258 & 0.3753 & 0.0530 & 0.0455 \\
Hidden 2 & 0.0377 & 0.2255 & 0.0895 & 0.0281 & 0.0520 & 0.3129 & 0.2408 & 0.0136 \\
Hidden 3 & 0.1802 & 0.0762 & 0.1292 & 0.1045 & 0.2299 & 0.1546 & 0.0241 & 0.1012 \\
Hidden 4 & 0.0845 & 0.0076 & 0.1517 & 0.2359 & 0.0647 & 0.1391 & 0.1097 & 0.2069 \\
Hidden 5 & 0.0817 & 0.1373 & 0.0100 & 0.1896 & 0.2711 & 0.1703 & 0.0224 & 0.1175 \\
Hidden 6 & 0.1372 & 0.0515 & 0.0443 & 0.0120 & 0.0072 & 0.2685 & 0.2368 & 0.2424 \\
Hidden 7 & 0.1060 & 0.1661 & 0.1411 & 0.0983 & 0.1197 & 0.1962 & 0.1704 & 0.0021 \\
Hidden 8 & 0.1118 & 0.1784 & 0.1186 & 0.0556 & 0.0120 & 0.1953 & 0.1709 & 0.1575 \\
Sum & 0.9198 & 1.0279 & 0.7552 & 0.7877 & 0.7823 & 1.8122 & 1.0281 & 0.8868 \\
\hline R.I. & $\mathbf{1 1 . 4 9 7}$ & $\mathbf{1 2 . 8 4 9}$ & $\mathbf{9 . 4 4 0}$ & $\mathbf{9 . 8 4 6}$ & $\mathbf{9 . 7 7 9}$ & $\mathbf{2 2 . 6 5 3}$ & $\mathbf{1 2 . 8 5 2}$ & $\mathbf{1 1 . 0 8 5}$ \\
\hline
\end{tabular}

The ranking of influence of the input parameters to the management competency rating were as follows: $\mathrm{B} 3<\mathrm{C} 5<\mathrm{B} 4<\mathrm{D} 8<\mathrm{A} 1<\mathrm{A} 2<\mathrm{D} 7<\mathrm{C} 6$. The $\mathrm{C} 6$ - Managing Innovation is the most influential parameter to the management competency while the B3 - people management and authentic leadership is the least influential parameter based on the respondents answer to the survey questionnaire tool as shown in Figure 6.

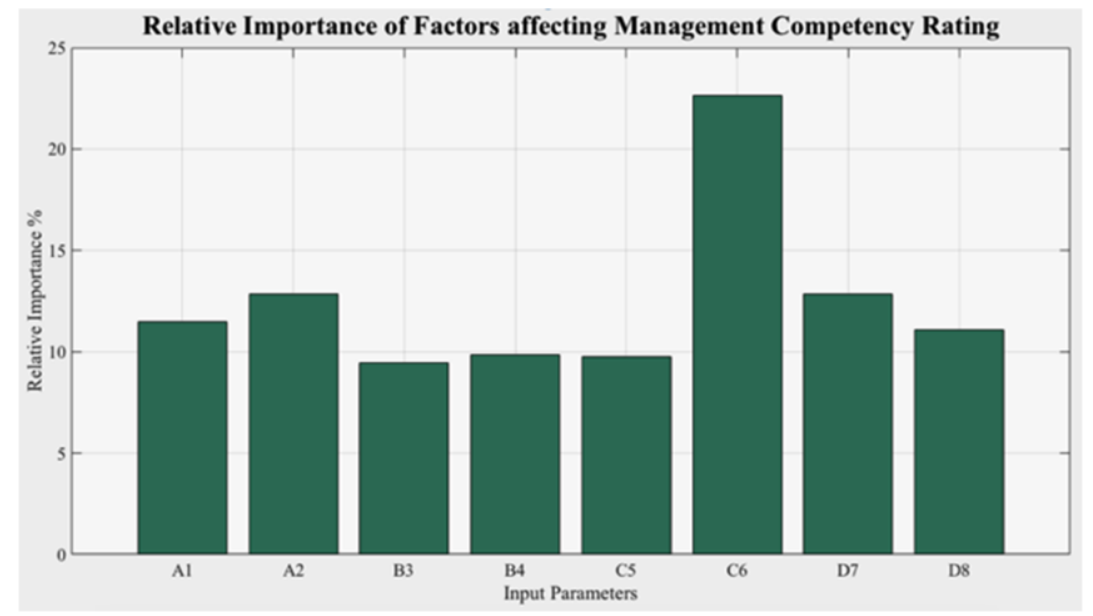

Figure 6. Relative Importance of Factors affecting Management Competency.

\section{Conclusion}

This study focused on developing a neural network model for predicting the management competency rating and the relative importance of factors affecting it. The study presents that the predicted results of the developed neural network model showed an excellent performance with high $\mathrm{R}_{\text {all }}$ and very low MSE and MAPE. It has final characteristics of 8-8-1 (input-hidden-output). The sensitivity analysis showed that the ranking of importance for the factors affecting management competency rating to be $\mathrm{B} 3<\mathrm{C} 5<\mathrm{B} 4<\mathrm{D} 8<\mathrm{A} 1<\mathrm{A} 2<\mathrm{D} 7<\mathrm{C} 6$. Overall, the neural network model created in this research yielded an excellent and accurate results in predicting the management 
competency rating as well as using its connection weights to calculate the influence of each input parameters to the management competency rating.

\section{Acknowledgments}

This paper acknowledges Mapua University for the support vital for the fulfillment of this research.

\section{References}

[1] Edum-Fotwe FT, McCaffer R. Developing project management competency: perspectives from the construction industry. Int J Proj Manag. 2000; 18(2): $111-24$.

[2] Silva D, Villaverde B, De Jesus KL, Marcial Jr, Ejera RL, Villa-Real CV, Zarrage JM. Design initiative implementation framework: A model integrating kolmogorov-smirnov in sustainable practices for triple-bottom-line principles in construction industry. Civ Eng Archit. 2020; 8(4): 599 - 617.

[3] Silva DL, Sabino LD, Lanuza DM, Adina EM, Villaverde BS, Pena EG. Silva's management competency theory: a factor-item analytic approach utilizing oblique rotation direct oblimin method under Kaiser-Bartlett's test of sphericity. In Proceedings of the World Congress on Engineering and Computer Science 2014 Vol. I WCECS 2014; 2014 Oct 22; San Francisco, CA. Vol. 24.

[4] Kulkami P, Londhe S, Deo M. Artificial neural networks for construction management: a review. J Soft Comput Civ Eng. 2017; 1(2): 70 - 88.

[5] Patel DA, Jha KN. Neural network model for the prediction of safe work behavior in construction projects. J Constr Eng Manag. 2015; 141(1): 04014066.

[6] Heravi G, Eslamdoost E. Applying artificial neural networks for measuring and predicting construction-labor productivity. J Constr Eng Manag. 2015; 141(10): 04015032.

[7] Wang D, Arditi D, Damci A. Construction project managers' motivators and human values. J Constr Eng Manag. 2017; 143(4): 04016115.

[8] Khanzadi M, Nasirzadeh F, Dashti MS. Fuzzy cognitive map approach to analyze causes of change orders in construction projects. J Constr Eng Manag. 2018; 144(2): 04017111.

[9] Kim GH, Seo DS, Kang KI. Hybrid models of neural networks and genetic algorithms for predicting preliminary cost estimates. J Comput Civ Eng. 2005; 19(2): $208-11$.

[10] Oreta AW, Kawashima K. Neural network modeling of confined compressive strength and strain of circular concrete columns. J Struct Eng. 2003; 129(4): $554-61$.

[11] Ullah S, Tanyu BF, Zainab B. Development of an artificial neural network (ANN)-based model to predict permanent deformation of base course containing reclaimed asphalt pavement (RAP). Road Mater Pavement Des. 2020; 1 - 19.

[12] Rinchon JPM, Concha NC, Calilung MGV. Reinforced concrete ultimate bond strength model using hybrid neural network-genetic algorithm. In 2017 IEEE 9th International Conference on Humanoid, Nanotechnology, Information Technology, Communication and Control, Environment and Management (HNICEM); 2017; $1-6$.

[13] Silva DL, de Jesus KLM, Villaverde BS, Adina EM. Hybrid Artificial Neural Network and Genetic Algorithm Model for Multi-Objective Strength Optimization of Concrete with Surkhi and Buntal Fiber. In Proceedings of the 2020 12th International Conference on Computer and Automation Engineering; $2020 ; 47-51$.

[14] Henríquez PA, Ruz GA. A non-iterative method for pruning hidden neurons in neural networks with random weights. Appl Soft Comput. 2018; 70: 1109-1121.

[15] Mountford GL, Atkinson PM, Dash J, Lankester T, Hubbard S. Sensitivity of Vegetation Phenological Parameters: From Satellite Sensors to Spatial Resolution and Temporal Compositing Period. In Sensitivity Analysis in Earth Observation Modelling; 2017; Elsevier; 75 - 90.

[16] Laroza Silva D, Marcelo De Jesus KL. Backpropagation Neural Network with Feature Sensitivity Analysis: Pothole Prediction Model for Flexible Pavements using Traffic and Climate Associated Factors. In 2020 the 3rd International Conference on Computing and Big Data; 2020; New York, NY, USA: Association for Computing Machinery, 60 - 67 . 